\title{
SENSIBILIDADE CROMOSSÔMICA À BLEOMICINA EM LINFÓCITOS DE PACIENTES COM SÍNDROME DE DOWN, NAS FASES G0, G1 E S DO CICLO CELULAR
}

\author{
Marlise Ladvocat Bartholomei-Santos \\ Centro de Biotecnologia \\ UFRGS - Porto Alegre, RS
}

\section{RESUMO}

Linfócitos de pacientes com Síndrome de Down (SD) apresentam uma frequência aumentada de aberrações cromossômicas após exposição à radiação ionizante nas fases $\mathrm{G}_{0}$ e $\mathrm{G}_{1}$ do ciclo celular. Entretanto, os linfócitos SD irradiados ou tratados com bleomicina (BLM) na fase $G_{2}$ não apresentam um aumento significativo da frequência de aberrações. BLM é uma droga radiomimética que vem sendo utlizada em experimentos citogenéticos para verificar a capacidade individual de reparo de DNA. O objetivo deste estudo foi analisar a sensibilidade cromossômica de pacientes com SD à $B L M$, nas fases $G_{0}, G_{1}$ e $S$ do ciclo celular. Foram feitas culturas de linfócitos, com e sem a droga, de 4 pacientes com SD e de 4 indivíduos normais, todos do sexo masculino e com idade inferior a 10 anos. Foram analisadas 100 metáfases mitóticas de cada tipo de cultura para cada indivíduo e foram registradas as aberrações cromossômicas e/ou cromatídicas. Os resultados obtidos mostram uma frequência mais alta de cromossomos dicêntricos, acêntricos, anéis e "double minutes" nas células $S D$ nas fases $G_{0}$ e $G_{1}$, mas não na fase $S$, em relação a células de indivíduos normais. Possivelmente, a fase do ciclo celular na qual a célula é 
tratada é o principal fator envolvido na sensibilidade cromossômica de linfócitos de pacientes com SD.

\section{ABSTRACT}

Lymphocytes from patients with Down Syndrome (DS) present an increased frequency of chromosome aberrations after exposition to ionizing radiation at $G_{0}$ and $G_{1}$ phases of the cell cycle. However, DS lymphocytes irradiated or treated with bleomycin (BLM) at $G_{2}$ phase do not

present a significant increase of aberration's frequency. BLM is a radiomimetic drug that has been used in cytogenetics experiments to verify the individual capacity of DNA repair. The aim of this study was to analyse the chromosome sensitivity from DS patients to $B L M$, at $G_{0}, G_{1}$ and $S$ phases of the cell cycle. Lymphocytes cultures were set up, with and without the drug, from 4 DS patients and 4 normal individuals, all of the male sex and age below 10. One hundred metaphases were analysed for each kind of culture for each individual and the chromosomal and/or chromatidic aberrations were registered. The results obtained show a higher frequency of dicentrics, rings, acentrics and double minutes in $D S$ cells at $G_{0}$ and $G_{1}$ phases, but not at $S$ phase, in relation to cells from normal individuals. Possibly, the phase of the cell cycle in which the cell is irradiated or treated is the main factor involved in chromosomal sensitivity of lymphocytes from DS patients.

\section{INTRODUÇÃO}

Linfócitos de pacientes com Síndrome de Down (SD) irradiados na fase $G_{0}$ e $G_{1}$ do ciclo celular apresentam uma frequência maior de cromossomos dicêntricos e anéis que linfócitos de pessoas normais (PRESTON, 1981; LEONĀRD \& MERZ, 1983; MORIMOTO et al., 1984). 
A fase do ciclo celular na qual a célula se encontra quando irradiada parece influir na frequência de aberrações cromossômicas em pacientes com SD. Em um estudo no qual linfócitos de pacientes com SD e de pessoas normais foram irradiados na fase $S$ do ciclo celular, as células SD apresentaram 1,3 vezes mais dicêntricos e anéis e 1,8 vezes mais deleções terminais que as células normais (ATHANASIOU \& BARTSOCAS, 1982).

SHAFIK et al. (1988) estudaram os efeitos da radiação ionizante em todas as fases do ciclo celular e verificaram que os linfócitos $S D$ foram significativamente mais sensíveis que os normais nas fases $G_{0}, G_{1}$ e $\mathrm{S}$ do ciclo celular. $\mathrm{Em} \mathrm{G}_{2}$, a resposta à radiação foi altamente variável na SD e não foi encontrada diferença significativa entre SD e normal. BARTHOLOMEI-SANTOS \& LUCCA (1997) também não encontraram diferença significativa entre linfócitos $\mathrm{SD}$ tratados com bleomicina na fase $\mathrm{G}_{2}$ e linfócitos normais.

DEKABAN et al. (1966) encontraram diferença no número de aberrações entre $S D$ e controle na fase $G_{0}$, mas não na fase $G_{2}$.

LEONARD \& MERZ (1983) também não encontraram diferença entre o grupo SD e o grupo controle, quando linfócitos foram irradiados em $G_{2}$, mas quando irradiados em $G_{1}$, a taxa de aberrações cromossômicas foi maior na SD.

É possivel que um mecanismo deficiente de reparo de DNA na SD aumente o risco de tais pacientes desenvolverem leucemia, através do acúmulo de danos genéticos causados por agentes físicos ou químicos presentes no meio ambiente. Como a leucemia é o único tipo de câncer que parece ocorrer em frequência aumentada na SD (FONG \& BRODEUR, 1987), uma atenção especial deve ser dada aos estudos com linfócitos destes pacientes.

A bleomicina (BLM) é um antibiótico radiomimético que vem sendo utilizado em experimentos citogenéticos para induzir quebras no DNA de linfócitos cultivados, com a finalidade de verificar a capacidade individual de reparo de DNA. 
Pacientes com vários tipos de câncer apresentam frequências maiores de aberrações cromossômicas induzidas por BLM que indivíduos normais (HSU et al.,1989). Sendo assim, torna-se importante verificar se indivíduos com predisposição ao desenvolvimento de neoplasias apresentam taxas elevadas de aberrações induzidas por esta droga.

O presente estudo teve como objetivos:

-Estudar os efeitos citogenéticos da BLM em linfócitos de pacientes com $S D$, nas fases $G_{0}, G_{1}$ e $S$ do ciclo celular, a fim de verificar se existem diferenças entre o número de aberrações induzidas em cada fase;

-Comparar as frequências de aberrações cromossômicas espontâneas e induzidas pela BLM entre pacientes com SD e grupo controle.

\section{MATERIAL E MÉTODOS}

Foram coletados $10 \mathrm{~mL}$ de sangue periférico de 4 pacientes com Síndrome de Down do sexo masculino, com idades de 3 meses, 4 (dois indivíduos) e 5 anos e de 4 controles normais do sexo masculino, com idades de 1, 5, 6 e 9 anos.

Para cada indivíduo foram feitas 4 culturas de linfócitos: sem tratamento, tratamento com BLM (concentração final $0,06 \mathrm{U} / \mathrm{mL}$ ) nas fases $\mathrm{G}_{0} \mathrm{G}_{1}$ e $\mathrm{S}$.

1) Tratamento na fase $G_{0}$ :

Os linfócitos foram incubados a $37^{\circ} \mathrm{C}$ com a droga em meio RPMI 1640, na ausência de soro fetal bovino (SFB) e fitohemaglutinina (PHA), por um período de 3 horas. Em seguida, os linfócitos foram lavados e cultivados em meio RPMI 1640, com SFB (20\%) e PHA (2\%) por 48 horas a $37^{\circ} \mathrm{C}$, quando então procedeu-se à colheita.

2) Tratamento na fase $G_{1}$ : 
Sete horas após a estimulação com PHA, os linfócitos foram incubados a $37^{\circ} \mathrm{C}$ com BLM em meio RPMI 1640, por um período de 1 hora, na ausência de PHA e SFB. Após a lavagem para retirada da droga, os linfócitos foram incubados por 41 horas em meio completo até a colheita.

3) Tratamento na fase $S$ :

Vinte e seis horas após a estimulação com PHA, os linfócitos foram incubados com BLM em meio RPMI 1640, por um período de 1 hora, na ausência de PHA e SFB. Após a lavagem para retirada da droga, os linfócitos foram incubados em meio completo por 22 horas até a colheita.

As colheitas foram realizadas centrifugando-se as culturas por 10 minutos a $1000 \mathrm{rpm}$. Ao material precipitado de cada cultura adicionouse $10 \mathrm{~mL}$ de solução hipotônica de $\mathrm{KCl} 0,075 \mathrm{M}$ e incubou-se a $37^{\circ} \mathrm{C}$ por 30 minutos. Em seguida, o material foi lavado 3 vezes com fixador (3 metanol:1 ácido acético) e 5 gotas da suspensão foram espalhadas em lâmina úmida e gelada. A coloração foi feita com Giemsa 3\% por 5 minutos.

Foram analisadas 100 metáfases mitóticas (em teste cego) de cada tipo de cultura para cada indivíduo e contadas as aberrações cromossômicas.

A análise estatística foi feita utilizando-se o teste t de Student.

\section{RESULTADOS E DISCUSSÃO}

Não se observaram aberrações cromossômicas espontâneas nas culturas de linfócitos dos 4 indivíduos normais e apenas um paciente com SD (número 2) apresentou uma única quebra cromatídica, não havendo diferença significativa entre os dois grupos $(t=1,0 ; 0,30<p<0,40)$. Estes resultados estão de acordo com os encontrados por PRESTON (1981); LEONARD \& MERZ (1983) e MORIMOTO et al. (1984), os quais também não encontraram diferenças significativas entre as frequências de aberrações cromossômicas espontâneas em linfócitos de indivíduos com $\mathrm{SD}$ e controles normais. 
As frequências de aberrações cromôssomicas induzidas por BLM encontradas em 100 metáfases mitóticas analisadas para cada indíviduo com SD e controles normais, nas fases $G_{0}, G_{1}$ e $S$ do ciclo celular estão expressas nas tabelas 1, 2 e 3, respectivamente.

As frequências de aberrações cromossômicas induzidas pela BLM em linfócitos na fase $G_{0}$ do ciclo celular foram maiores nos pacientes com SD do que nos controles ( $t=4,74 ; p<0,05$ ), assim como em linfócitos na fase $G_{1}(t=2,45 ; p<0,05)$. Resultados semelhantes são encontrados na literatura para linfócitos irradiados de pacientes com SD (PRESTON, 1981; LEONARD \& MERZ, 1983). Entretanto, na fase $S$ não foi observada diferença significativa entre os dois grupos estudados $(t=1,31 ; 0,20<p<$ 0,30 ), em contraste aos resultados encontrados por ATHANASIOU \& BARTSOCAS (1982) e SHAFIK et al. (1988), os quais observaram uma maior frequência de aberrações induzidas por radiação em linfócitos SD.

A porcentagem de metáfases apresentando alterações cromossômicas foi maior nos indivíduos com SD, quando comparados aos controles, para as fases $G_{0}(t=3,57 ; p<0,05)$ e $G_{1}(t=4,58 ; p<0,05)$, mas não se observou diferença significativa para a fase $S(t=1,59 ; 0,20<p<$ $0,30)$.

Não se verificou diferença significativa na sensibilidade de linfócitos trissômicos à $B L M$ nas fases $G_{0}$ e $G_{1}$ do ciclo celular $(t=1,78$; $0,10<p<0,20$ ). Linfócitos normais mostraram maior sensibilidade à BLM na fase $G_{0}(t=5,31 ; p<0,05)$, entretanto, LEONARD \& MERZ (1983) encontraram maior sensibilidade à radiação nos linfócitos trissômicos e nos normais em $\mathrm{G}_{1}$.

A frequência de aberrações induzidas nos linfócitos SD foi maior na fase $G_{0}$ que na fase $S(t=3,85 ; p<0,05)$, mas não houve diferença entre as fases $G_{1}$ e $S(t=0,90 ; 0,40<p<0,50)$. Resultados semelhantes foram observados nos linfócitos normais $(t=8,0 ; p<0,05$ e $t=$ 0,$08 ; 0,90<p<1,0$, respectivamente). 
A figura 1 apresenta comparações entre as frequências dos tipos mais observados de aberrações (cromossomos dicêntricos, anéis, fragmentos acêntricos e "double minutes" ) em pacientes com SD e em controles.

Interessantemente, os "double-minutes" apareceram em alta frequência nas células trissômicas tratadas com BLM e não foram encontrados nos linfócitos normais. A figura 2 apresenta comparações entre as frequências de aberrações nas fases $\mathrm{G}_{0}$ e $\mathrm{G}_{1}$.

A fase do ciclo celular na qual os linfócitos trissômicos são tratados parece influir na sensibilidade cromossômica à $B L M$ e à radiação. $A$ maior sensibilidade à $B L M$ verificada neste estudo em células nas fases $G_{0}$ e $G_{1}$, e a ausência de sensibilidade aumentada em linfócitos SD na fase $G_{2}$ (BARTHOLOMEI-SANTOS \& LUCCA, 1997), quando comparada à sensibilidade de linfócitos normais, estão de acordo com os resultados citados na literatura para células tratadas com raios $X$ ou $\gamma$. LEONARD \& MERZ (1983) observaram que linfócitos normais entravam em um período de radiossensibilidade cromossômica aumentada 8 horas após o estímulo por PHA. Assim, o período reduzido de transformação blástica na trissomia 21 pode ter resultado na perda do período inicial de menor sensibilidade observado nos linfócitos normais. Os autores sugeriram que diferenças na radiossensibilidade cromossômica entre linfócitos normais e SD existem somente antes e durante a transformação blástica, pois as frequências de aberrações induzidas, quando linfócitos normais são irradiados oito horas após estímulo por PHA, são comparáveis às induzidas em linfócitos SD irradiados 30 minutos após a estimulação.

Os resultados encontrados no presente estudo, assim como os previamente obtidos em linfócitos na fase $\mathrm{G}_{2}$ de indivíduos com SD (BARTHOLOMEI-SANTOS \& LUCCA, 1997) estão de acordo com a sugestão de LEONARD \& MERZ (1983). 


\section{Fase G0}

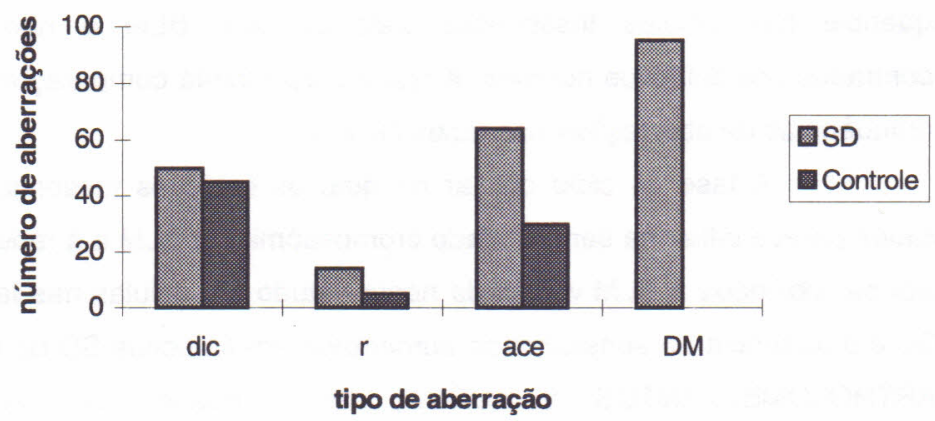

\section{Fase G1}

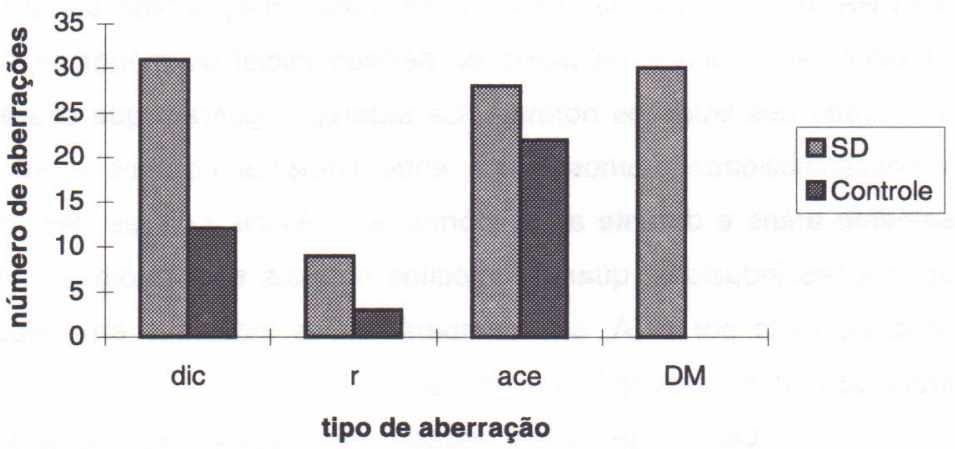

Figura 1. Histogramas das frequências de cromossomos dicêntricos (dic), anéis (r), fragmentos acêntricos (ace) e "double minutes" (DM) em linfócitos de indivíduos com $\mathrm{SD}$ e controles normais, nas fases $\mathrm{G}_{0}$ e $\mathrm{G}_{1}$ do ciclo celular 
SD

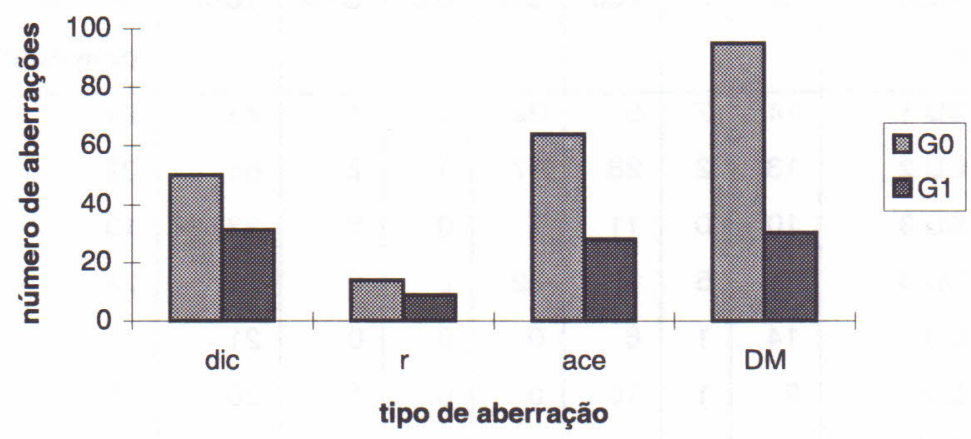

Controle

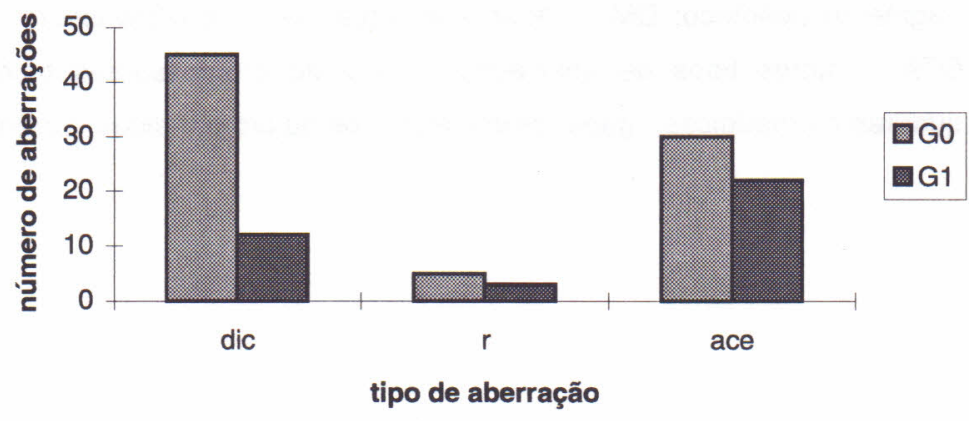

Figura 2. Histogramas das frequências de cromossomos dicêntricos (dic), anéis ( $r$ ), fragmentos acêntricos (ace) e "double minutes" (DM) em linfócitos nas fases $\mathrm{G}_{0}$ e $\mathrm{G}_{1}$ de indivíduos com SD e controles normais. 
TABELA 1. Frequências absolutas de aberrações cromossômicas em linfócitos tratados com BLM na fase $\mathrm{G}_{0}$ de pacientes com SD e controles normais (c)

\begin{tabular}{|l|l|l|l|l|l|l|l|l|}
\hline Indivídu & dic & $\mathbf{r}$ & ace & DM & iso & OTA & Total & $\begin{array}{l}\% \text { de células } \\
\text { com aberrações }\end{array}$ \\
\hline SD 1 & 14 & 7 & 9 & 39 & 0 & 4 & 73 & 21 \\
SD 2 & 13 & 2 & 28 & 17 & 4 & 2 & 66 & 22 \\
SD 3 & 10 & 0 & 11 & 7 & 0 & 5 & 33 & 19 \\
SD 4 & 13 & 5 & 16 & 32 & 0 & 6 & 71 & 24 \\
C 1 & 14 & 1 & 6 & 0 & 0 & 0 & 21 & 11 \\
C 2 & 9 & 1 & 10 & 0 & 0 & 1 & 20 & 15 \\
C 3 & 10 & 1 & 6 & 0 & 0 & 1 & 18 & 16 \\
C 4 & 12 & 2 & 8 & 0 & 0 & 0 & 22 & 16 \\
\hline
\end{tabular}

* Abreviações: dic = cromossomo dicêntrico; $r$ = cromossomo em anel; ace = fragmento acêntrico; DM = "double minutes"; iso = quebra isocromatídica; OTA = outros tipos de aberrações (incluindo cromossomos tricêntricos, quebras cromatídicas, "gaps" cromossômicos ou cromatídicos, trirrádios). 
TABELA 2. Frequências absolutas de aberrações cromossômicas em linfócitos tratados com BLM na fase $\mathrm{G}_{1}$ de pacientes com SD e controles normais (C)

\begin{tabular}{|l|l|l|l|l|l|l|l|l|}
\hline Indivíduo & dic & r & ace & DM & iso & OTA & Total & $\begin{array}{l}\text { de células } \\
\text { com aberrações }\end{array}$ \\
\hline SD 1 & 8 & 5 & 9 & 17 & 6 & 16 & 61 & 18 \\
SD 2 & 2 & 0 & 3 & 0 & 0 & 3 & 8 & 8 \\
SD 3 & 12 & 4 & 9 & 10 & 0 & 6 & 41 & 20 \\
SD 4 & 9 & 0 & 7 & 3 & 3 & 2 & 24 & 16 \\
C 1 & 3 & 1 & 12 & 0 & 0 & 0 & 16 & 10 \\
C 2 & 2 & 0 & 2 & 0 & 2 & 0 & 6 & 4 \\
C 3 & 3 & 1 & 4 & 0 & 0 & 0 & 8 & 7 \\
C 4 & 4 & 1 & 4 & 0 & 1 & 0 & 10 & 8 \\
\hline
\end{tabular}

* Abreviações: dic $=$ cromossomo dicêntrico; $r=$ cromossomo em anel; ace $=$ fragmento acêntrico; $\mathrm{DM}$ = "double minutes"; iso = quebra isocromatídica; OTA = outros tipos de aberrações (incluindo cromossomos tricêntricos, quebras cromatídicas, "gaps" cromossômicos ou cromatídicos, trirrádios). 
TABELA 3. Frequências absolutas de aberrações cromossômicas em linfócitos tratados com BLM na fase $S$ de pacientes com SD e controles normais (C)

\begin{tabular}{|l|l|l|l|l|l|l|l|l|}
\hline Indivíduo & dic & ctb & ace & DM & iso & OTA & Total & $\begin{array}{l}\text { de células } \\
\text { com } \\
\text { aberrações }\end{array}$ \\
\hline SD 1 & 0 & 5 & 2 & 0 & 0 & 2 & 9 & 8 \\
SD 2 & 2 & 7 & 2 & 1 & 0 & 2 & 14 & 13 \\
SD 3 & 0 & 6 & 2 & 4 & 0 & 5 & 17 & 14 \\
SD 4 & 5 & 0 & 3 & 5 & 1 & 25 & 39 & 16 \\
C 1 & 0 & 6 & 0 & 0 & 0 & 4 & 10 & 9 \\
C 2 & 0 & 9 & 4 & 0 & 0 & 0 & 13 & 12 \\
C 3 & 0 & 7 & 3 & 0 & 0 & 1 & 11 & 10 \\
C 4 & 2 & 9 & 4 & 0 & 0 & 0 & 15 & 13 \\
\hline
\end{tabular}

* Abreviações: dic = cromossomo dicêntrico; $\mathrm{ctb}=$ quebra cromatídica; ace = fragmento acêntrico; DM = "double minutes"; iso = quebra isocromatídica; OTA = outros tipos de aberrações (incluindo cromossomos tricêntricos, cromossomos em anel, "gaps" cromossômicos ou cromatídicos, trirrádios). 


\section{AGRADECIMENTO}

À Fundação Universidade do Rio Grande (FURG) pelas condições fornecidas para a realização deste projeto

\section{REFERÊNCIAS BIBLIOGRÁFICAS}

ATHANASIOU, K.; BARTSOCAS, C.S. The implications of S-phase exchanges for the mechanisms of radiosensitivity in trisomy 21. Am. J. Med. Genet., v.12, p.141-146, 1982.

BARTHOLOMEI-SANTOS, M.L. \& LUCCA, E.J. Chromosome sensitivity to bleomycin in G2 lymphocytes from Down Syndrome patients. Braz. J. Genetics, v.20, p.79-85, 1997.

DEKABAN, A.S.; THRON, R.; STEUSING, J.K. Chromosomal aberrations in irradiated blood and blood cultures of normal subjects and of selected patients with chromosomal abnormality. Radiation Res., v.27, p.5063, 1966.

FONG, C. \& BRODEUR, G. M. Down's syndrome and leukemia: leukemogenesis. Cancer Cytogenet., v.28, p55-76, 1987.

HSU, T.C.; JOHNSTON, D.A.; CHERRY, L.M.; RAMKISSOON, D.; SCHANTZ, S.P.; JESSUP, J.M.; WINN, R.J.; SHIRLEY, L.; FURLONG, C. Sensitivity to genotoxic effects of bleomycin in humans: possible relationship to environmental carcinogenesis. Int. J. Cancer, v.43, p.403-409, 1989.

LEONARD, J.C.; MERZ, T. The influence of cell cycle kinetics on the radiosensitivity of Down syndrome lymphocytes. Mutat. Res., v.109, p.111-121, 1983. 
MORIMOTO, K.; KANEKO, T.; IIJIMA, K.; KOIZUMI, A. Proliferative kinetics and chromosome damage in trisomy 21 lymphocyte cultures exposed to $\gamma$-rays and bleomycin. Cancer Res., v.44; p.1499-1504, 1984.

PRESTON, R.J. X-ray-induced chromosome aberrations in Down lymphocytes: an explanation of their increased sensitivity. Environ. Mutagen., v.3, p.85-89, 1981.

SHAFIK, H.M.; AU, W.W.; LEGATOR, M.S. Chromosomal radiosensitivity of Down syndrome lymphocytes at different stages of the cell cycle. Hum. Genet., v.78, p.71-75, 1988. 